\title{
Radical computing in Japan
}

\section{Tokyo}

NEURAL, biological and optical computing are among the radical forms of computing to be taken up by a new international institute to be set up in Japan with the backing of the private sector. The institute is the work of the Japan Technology Transfer Association (JTTAS), a non-profit organization affiliated with the Ministry of International Trade and Industry (MITI), and has already won support from a large number of Japanese companies.

The aims of the International Institute of Novel Computing (IINC), as it will be named, appear to overlap with the socalled sixth-generation computer project which MITI is expected to launch in 1992 (see Nature 345, 279; 1990). But backers of IINC say the two projects are not directly related.

JTTAS, which is affiliated with MITI's Agency of Industrial Science and Technology (AIST) but funded almost entirely by private industry, began soliciting contributions last April from private companies for a feasibility study for IINC. The association's activities initially angered MITI's machinery and information industries bureau which is promoting the sixth generation project. According to Taizo Nishikawa of the bureau's industrial electronics division, JTTAS was giving the impression that the IINC project is officially backed by MITI when in fact it is not (part of the problem was that JTTAS is affiliated to a different section of MITI).
But Hideo Aiso of Keio University, the chairman of IINC, says that there is no real conflict with MITI. The two projects, he says, are like "two vectors" going in different directions although it is possible they could merge in the future. (Oddly enough, many of the academic advisers for IINC are also advising MITI on its project)

Aiso says that previous national computing projects, such as the fifth-generation computer project, have tended to set their sights on making a particular piece of hardware, something which is necessary to get backing from the Ministry of Finance. But IINC supporters, such as Shunichi Amari of Tokyo University, one of Japan's leading experts on neural computing, see a need for a more flexible approach that will allow more basic research and may also encourage the participation of foreign researchers. They think the best way to achieve that goal is to avoid government funding at least in the initial phase of the project.

Nine companies, including Sanyo, Hitachi, Nippon Steel Corporation, Mitsubishi Electric and Nissan, have already agreed to contribute $¥ 1.8$ million $(\$ 13,000)$ a year towards the IINC feasibility study, which will last "about two years", according to Aiso. And many more, including Toyota, NEC, IBM Japan, Honda, Fujitsu, Sharp, Sony, Tokyo Gas Co., Japan Railways and Nippon Telegraph and Telephone Cor-

\section{Call for increased polytechnic spending}

\section{London}

ThE UK Polytechnics and Colleges Funding Council (PCFC) should increase its spending on research from the current $£ 30$ million a year to $£ 58$ million in 1991-92, according to the report from a PCFCappointed committee, released today (20 September).

The research committee was set up in April last year by the newly formed PCFC to examine the future role of research in the polytechnic and college sector. Its chairman, Oscar Roith, chief scientist at the UK Department of Trade and Industry, says that many committee members were at first sceptical of the value of polytechnic research. But he claims that all are now convinced that research is "a key component" of polytechnics and colleges.

A survey by an independent team of consultants found that the sector's external research income exceeds that from PCFC by 1.7 to 1 . The committee believes that increasing PCFC's spending on research would attract more research funds from industry and the research councils.
Polytechnics and colleges received only $£ 6.7$ million in research council grants in 1988-89 (about 4 per cent of the councils' annual research grant expenditure).

To increase this, PCFC is to set up a working party to look at the polytechnics' relationship with the research councils. Roith says that polytechnic researchers often do not apply to research councils because they believe university applicants are favoured. But Roith says that the research councils assured his committee that this was not the case.

Nevertheless, universities do have a real financial advantage. Research council grants provide only for the direct costs of research, but polytechnics receive no government funds for research overheads. Universities, by contrast, benefit from the 'dual support' system, where research council grants are supplemented by the research component of the Universities Funding Council (UFC) block grants. In 1988-89, universities spent about $£ 770$ million of their UFC income on research.

Peter Aldhous
European body gearing up

\section{London}

JoHN Lake, formerly head of science with the UK Agricultural and Food Research Council, is to become the first director of the European Environmental Research Organization (EERO). EERO was conceived as an analogue to the European Molecular Biology Organization, to support basic research in environmental science. It has about $\mathbf{4 0}$ members, all eminent European environmental scientists, and a small permanent office in Wageningen in the Netherlands.

Lake says that EERO-supported research must be led by the opportunity of making new scientific discoveries, rather than responding to political demands. Applications for EERO's first round of up to 15 fellowships have just closed. Lake hopes to increase EERO's current annual budget of 2.5 million ECU $(1 \mathrm{ECU}=£ 0.70)$ by "several fold" over the next few years, raising funds from European governments and charitable foundations. The Dutch government and the Volkswagen Foundation have already given support.

Peter Aldhous

poration are shortly expected to join, says Isao Idota, managing director of JTTAS. JTTAS's final target is 100 companies.

Twelve subcommittees each with about 20 academics and industrialists have been established for the feasibility study and they have already begun regular meetings. The subcommitees, headed by leading academics in each field, cover neurocomputing, biocomputing, optical computing and parallel computing as well as several other fields. Thus, the research areas overlap in many respects with the sixth generation project. But Aiso does not expect all of these areas to be covered when the institute finally opens.

Each subcommittee has members from the companies supporting IINC and also several foreign "observers" who will be kept informed of subcommittee deliberations and will be tapped for advice. Among them are Terence Sejnowski of the Salk Institute in the United States and Harold Szu of NASA.

Aiso and Amari say they are determined to make the institute truly international. There have been several recent attempts by MITI to set up so-called "international" institutes but they have failed to draw support from foreign companies and have been unable to recruit significant numbers of foreign researchers.

Aiso and Amari say that the solution may be to establish an institute in the United States and Europe first and only later set one up in Japan.

David Swlnbanks 